\title{
XPO1-mutant NSCLC without STK11/ KEAP1 mutations may predict better survival to immunotherapy
}

\author{
Xuanzong $\mathrm{Li}^{1,2}{ }^{-}$, Bing Zou ${ }^{2}$, Shijiang Wang ${ }^{2}$, Linlin Wang ${ }^{2 *}$ and Jinming Yu ${ }^{2}$
}

To the editor,

The nuclear export protein XPO1 regulates the export of a range of cargoes from the nucleus to the cytoplasm, and plays an important role in the maintenance of cellular homeostasis [1]. Previous studies suggested that XPO1 mutations participate in several steps of oncogenesis among multiple cancer types, and XPO1-mutant non-small-cell lung cancer (NSCLC) were associated with poorer survival contrast to their counterparts [2]. Therefore, finding novel strategies is urgently needed to improve the prognosis for XPO1-mutant NSCLC patients.

Up to now, the application of XPO1 blockade is challenging, and the definite efficacy for XPO1-inhibitors is still undetermined in NSCLC [1]. On the other hand, immune checkpoint inhibitors (ICIs)-based immunotherapies have changed the landscape of anti-cancer treatments, whereas the usage of immunotherapeutic agents should be careful in patients harboring driver mutations. Interestingly, Misako et al. demonstrated that NSCLC patients with XPO1 mutations were more likely to have high tumor mutational burden (TMB), which suggested that ICIs could serve as an option for these patients [2]. Nonetheless, to our best knowledge, there was no study reported the efficacy of ICIs in NSCLC patients with XPO1 mutations.

\footnotetext{
*Correspondence: wanglinlinatjn@163.com

${ }^{2}$ Department of Radiation Oncology, Shandong Cancer Hospital

and Institute, Shandong First Medical University and Shandong Academy of Medical Sciences, Jinan, China

Full list of author information is available at the end of the article
}

Using public databases, the prognostic values of several rare driver mutations were described in NSCLC patients with ICIs treatment. In this study, we integrated the MSK-TMB, POPLAR and OAK cohorts to evaluate the association between XPO1 mutation and the responses of NSCLC patients receiving ICIs [3, 4]. A total of 350 ICI-treated NSCLC patients from the MSK-TMB cohort and 429 atezolizumab-treated NSCLC patients with available genomic sequencing data (biomarker evaluable population) from the POPLAR and OAK cohorts were included in this study. Importantly, XPO1 mutations were defined as any nonsynonymous or fusion mutations. Our results showed that the incidence of XPO1 mutations was $1.2 \%$ (9 of $779)$ in the entire cohort. The clinical characteristics and the corresponding survival outcomes of the nine XPO1-mutant NSCLC patients were described in Table 1. In detail, most of patients were non-squamous (6 of $9,66.7 \%$ ), were male (7 of $9,77.8 \%$ ), had missense mutation type for XPO1 gene (7 of 9, 77.8\%) and exhibited high TMB scores (above 10 mutations/Mb) (7 of 9, 77.8\%). At first, we analyzed the overall survival (OS) in NSCLC patients with XPO1 mutations and their wild type counterparts. Unfortunately, we found patients harboring XPO1 mutations had comparable OS compared with those without the mutation (median OS, 19 months versus 12 months, $\mathrm{p}=0.186$; Fig. 1A). Notably, comutations of STK11/KEAP1 is common among NSCLC patients harbored XPO1 mutations [2], and NSCLC patients with STK11/KEAP1 mutations were associated with the inferior efficacy of ICIs which demonstrated both in MSK-TMB/POPLAR/ original author(s) and the source, provide a link to the Creative Commons licence, and indicate if changes were made. The images or other third party material in this article are included in the article's Creative Commons licence, unless indicated otherwise in a credit line to the material. If material is not included in the article's Creative Commons licence and your intended use is not permitted by statutory regulation or exceeds the permitted use, you will need to obtain permission directly from the copyright holder. To view a copy of this licence, visit http://creativecommons.org/licenses/by/4.0/. The Creative Commons Public Domain Dedication waiver (http://creativeco mmons.org/publicdomain/zero/1.0/) applies to the data made available in this article, unless otherwise stated in a credit line to the data. 
Table 1 Clinical characteristics of XPO1 mutant NSCLC patients with immunotherapy

\begin{tabular}{|c|c|c|c|c|c|c|c|c|c|}
\hline Patient & Study & Histology & Sex & $\begin{array}{l}\text { XPO1 mutation } \\
\text { (protein change) }\end{array}$ & Mutation type & $\begin{array}{l}\text { TMB } \\
\text { (mutations/ } \\
\text { Mb) }\end{array}$ & $\begin{array}{l}\text { STK11/KEAP1 } \\
\text { mutation }\end{array}$ & OS (months) & $\begin{array}{l}\text { OS } \\
\text { status }\end{array}$ \\
\hline A & MSK-TMB & Squamous & Male & c. $2461 C>$ G (Q821E) & Missense & 7.87 & No & 18 & Living \\
\hline B & MSK-TMB & Adenocarcinoma & Male & c. $1087 \mathrm{~A}>\mathrm{G}(\mathrm{T} 363 \mathrm{~A})$ & Missense & 22.63 & No & 21 & Living \\
\hline C & MSK-TMB & Adenocarcinoma & Male & c.1211C > G (P404R) & Missense & 11.81 & STK11 & 6 & Dead \\
\hline D & MSK-TMB & Adenocarcinoma & Female & c.1003C > G (Q335E) & Missense & 10.82 & No & 13 & Living \\
\hline E & MSK-TMB & Squamous & Male & XPO1-USP34 fusion & Fusion & 7.87 & No & 19 & Dead \\
\hline $\mathrm{F}$ & POPLAR & Squamous & Male & c.2977C > G (Q993E) & Missense & 44 & No & 23 & Living \\
\hline G & POPLAR & Non-squamous & Female & c.1434G > C (E478D) & Missense & 49 & No & 16 & Dead \\
\hline $\mathrm{H}$ & OAK & Non-squamous & Male & c. $2461 C>T\left(Q 821^{*}\right)$ & Nonsense & 62 & No & 21 & Living \\
\hline । & OAK & Non-squamous & Male & c.1925G > T (G642V) & Missense & 20 & KEAP1 & 4 & Dead \\
\hline
\end{tabular}

NSCLC non-small-cell lung cancer, TMB tumor mutational burden, OS overall survival
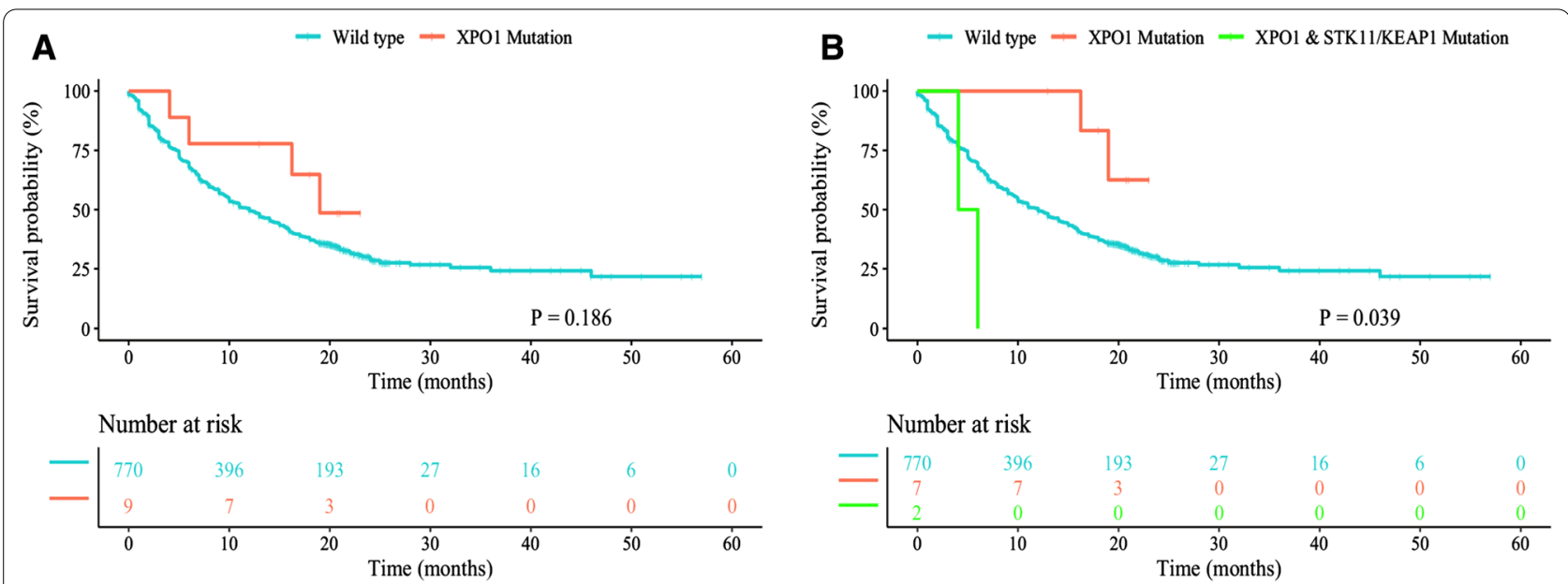

Fig. 1 The prognostic value of XPO1 mutations in NSCLC patients with immune checkpoint inhibitors. A Kaplan-Meier curve comparing OS of NSCLC patients with XPO1 mutations and their wild type counterparts. B Kaplan-Meier curve comparing OS of NSCLC patients with pure XPO1 mutations, wild type and comutation of STK11/KEAP1 with XPO1 mutations. OS, overall survival; NSCLC, non-small-cell lung cancer

OAK cohorts and other studies [5]. Hence, we further divided our patients into pure XPO1-mutant, wild type and XPO1-STK11/KEAP1 mutant groups. Surprisingly, NSCLC patients with pure XPO1 mutations had significantly longer OS than wild type and XPO1-STK11/ KEAP1 mutant cohorts (median OS, not reached versus 12 months versus 4 months, $\mathrm{p}=0.039$; Fig. 1B).

Collectively, for the first time, we investigated the role of XPO1 mutations in NSCLC patients with ICIs treatment. Our results suggested that there was no significant difference in the efficacy of ICIs therapy between NSCLC patients with and without XPO1 mutations. However, considering the co-mutation status of STK11/KEAP1, we demonstrated that patients with pure XPO1 mutations were correlated with longer survival and could serve as a favorable prognostic biomarker in NSCLC. Nevertheless, the small sample of XPO1-mutant NSCLC patients should not be neglected, and further studies will be necessary to verify our results.

\section{Acknowledgements \\ None.}

\section{Authors' contributions}

XL performed data analysis and manuscript preparation. BZ, SW, LW and JY re-verified the data and polished the language. LW designed the study and revised the manuscript. All authors read and approved the final manuscript.

\section{Funding}

The study was supported by funds from The National Key Research and Development Projects of China (2018YFC1312201), Radiation Oncology Innovate Unit, Chinese Academy of Medical Sciences (2019RU071), the Academic

Promotion Program of Shandong First Medical University (2019ZL002) and 
the foundation of National Natural Science Foundation of China (81972863, 81627901 and 82030082).

\section{Availability of data and materials}

The data are available from the corresponding authors upon reasonable request.

\section{Declarations}

\section{Ethics approval and consent to participate}

Since the study is based on public data, the informed consent and ethical proof are not required.

\section{Consent for publication}

All authors give their consent to publish this manuscript.

\section{Competing interests}

The author declared no competing interests.

\section{Author details}

'Department of Radiation Oncology, Affiliated Tumor Hospital of Xinjiang Medical University, Urumqi, China. ${ }^{2}$ Department of Radiation Oncology, Shandong Cancer Hospital and Institute, Shandong First Medical University and Shandong Academy of Medical Sciences, Jinan, China.

Received: 21 September 2021 Accepted: 28 September 2021 Published online: 09 October 2021

\section{References}

1. Azmi AS, Uddin MH, Mohammad RM. The nuclear export protein XPO1from biology to targeted therapy. Nat Rev Clin Oncol. 2021;18:152-69.

2. Nagasaka M, Asad MFB, Al Hallak MN, Uddin MH, Sukari A, Baca Y, Xiu J, Magee D, Mamdani H, Uprety D, et al. Impact of XPO1 mutations on survival outcomes in metastatic non-small cell lung cancer (NSCLC). Lung Cancer. 2021;160:92-8.

3. Gandara DR, Paul SM, Kowanetz M, Schleifman E, Zou W, Li Y, Rittmeyer A, Fehrenbacher L, Otto G, Malboeuf C, et al. Blood-based tumor mutational burden as a predictor of clinical benefit in non-small-cell lung cancer patients treated with atezolizumab. Nat Med. 2018;24:1441-8.

4. Samstein RM, Lee CH, Shoushtari AN, Hellmann MD, Shen R, Janjigian YY, Barron DA, Zehir A, Jordan EJ, Omuro A, et al. Tumor mutational load predicts survival after immunotherapy across multiple cancer types. Nat Genet. 2019;51:202-6.

5. Shang X, Li Z, Sun J, Zhao C, Lin J, Wang H. Survival analysis for nonsquamous NSCLC patients harbored STK1 1 or KEAP1 mutation receiving atezolizumab. Lung Cancer. 2021;154:105-12.

\section{Publisher's Note}

Springer Nature remains neutral with regard to jurisdictional claims in published maps and institutional affiliations.
Ready to submit your research? Choose BMC and benefit from:

- fast, convenient online submission

- thorough peer review by experienced researchers in your field

- rapid publication on acceptance

- support for research data, including large and complex data types

- gold Open Access which fosters wider collaboration and increased citations

- maximum visibility for your research: over 100M website views per year

At BMC, research is always in progress.

Learn more biomedcentral.com/submissions 